$\mathrm{KCP}--613-4525$

DE91 011377

\title{
ENTERPRISE MODELING FOR THE FOCUSED ELECTRONICS FACTORY
}

Brian N. Oliver

Published April 1991

Paper submitted to Kansas City KnowledgeWare Users Group

December 13, 1990

Kansas City, Missouri

Technical Communications

Kansas City Division 


\section{DISCLAIMER}

This report was prepared as an account of work sponsored by an agency of the United States Government. Neither the United States Government nor any agency Thereof, nor any of their employees, makes any warranty, express or implied, or assumes any legal liability or responsibility for the accuracy, completeness, or usefulness of any information, apparatus, product, or process disclosed, or represents that its use would not infringe privately owned rights. Reference herein to any specific commercial product, process, or service by trade name, trademark, manufacturer, or otherwise does not necessarily constitute or imply its endorsement, recommendation, or favoring by the United States Government or any agency thereof. The views and opinions of authors expressed herein do not necessarily state or reflect those of the United States Government or any agency thereof. 


\section{DISCLAIMER}

Portions of this document may be illegible in electronic image products. Images are produced from the best available original document. 


\section{Enterprise Modeling \\ For The Focused Electronics Factory \\ Presented to: \\ Kansas City Knowledgeware Users Group \\ December 13, 1990}

Presentor: Brian N. Oliver

Allied-Signal, Inc. Kansas City Division (*)

(*) Operated for the United states Department of Energy Under Contract Number DE-AC04-76-DP00613 
Enterprise Modeling For The Focused Electronics Factory

INTRODUCTION

The Allied-Signal, Inc., Kansas City Division, has operated a manufacturing facility in Kansas city for over 40 years and currently employs approximately 6,000 people.

They recently completed a comprehensive strategic systems planning activity. This activity has resulted in a Information systems Integration Plan which will be implemented over the next six years.

The Coopers \& Lybrand CIMPLAN methodology was applied which focuses on manufacturing business practices. Several key deliverables from this project included an enterprise function and data model. The Information Engineering Workbench (IEW) planning and analysis tools, from knowledgeware, Inc., were used to manage and document the models.

Model Manager, Brian Oliver, will present an overview of how IEW was used in this multiple system project modeling activity. Brian will share with us the methods used, results, and lessons learned. 
Enterprise Modeling For The Focused Electronics Factory

SIIDE 1: Enterprise Modeling For The Focused Electronics Factory

The Allied-Signal, Inc., Kansas City Division, has established a set of strategic goals; one of which is to achieve World class Manufacturing status.

In todays society of high technology, we are all trying to achieve a competitive edge.

The ideas that I am going to share with you today will demonstrate how the Kansas city Division is striving to achieve World class Manufacturing status.

To help achieve this status, the Focused Electronics Factory effort was initiated. 
Enterprise Modeling For The Focused Electronics Factory

\section{SLIDE 2: Agenda}

I'll be giving you a little background information about the effort and the development methods used during this effort including a list of the sub-projects identified.

I'll focus on how we managed and coordinated the large quantity of information generated by the sub-projects and discuss a project/enterprise model encyclopedia lifecycle.

I'll conclude the presentation with some project statistics and a few lessons we learned during the planning and analysis activities. 
Enterprise Modeling For The Focused Electronics Factory

SLIDE 3: Background - Purpose

The Focused Electronics Factory (FEF) is a strategic Business Improvement Initiative aimed at streamlining and simplifying the operations and Systems for Electronic and Electrical Product Manufacturing.

This effort was conceived on May 1988 and after some initial planning and training activities, the consulting firm of coopers \& Lybrand was contracted on January 1989. They assisted the Kansas City Division in a twenty-one month Computer Integrated Manufacturing project focusing on our Electronic and Electrical Manufacturing Business Functions. 
Enterprise Modeling For The Focused Electronics Factory

\begin{abstract}
SLIDE 4: Background - Focused Electronics Factory - Context Diagram
\end{abstract}

A project scope was established and the business functions within this scope were divided into two areas; Engineering Functions and Plant Management, Control, and Production Functions.

Some of the key Engineering Functions include: guality Engineering, Electronic Engineering, and Component Engineering.

Key Plant Management, Control, and Production Functions include: Electronic Production, Purchased Electronic Components, and cost and Inventory Accounting.

The functions outside the project scope were only considered when information was required from or requested by the functions.

As you can see, the Kansas City Division is a prime contractor for the Department of Energy (DOE) and, as such, the company is required by law to follow several governmental regulations.

We also interface with several DOE Design Agencies and order 
Enterprise Modeling For The Focused Electronics Factory

components from multiple suppliers. 
Enterprise Modeling For The Focused Electronics Factory

SLIDE 5: Background - FEF Organizational structure

The organizational structure developed to support the Focused Electronics Factory consists of a matrix management organization with resources supplied by the line management organizations.

The FEF Project Manager directly reports project status to the Vice President and interfaces with the consultant Manager from Coopers \& Lybrand (C\&L).

The FEF steering committee consists of the corporate managers who provide input on the companies goals and direction and they review major FEF project deliverables.

The Information systems (IS) steering Committee consists of information systems managers who provide input on how the Strategic Information Systems should be specified, developed, integrated, and implemented, and they review minor and major FEF project deliverables.

The remaining FEF resources were positioned in one of three teams: The Business systems Team, The People systems Team, and the Information systems Team. 
Enterprise Modeling For The Focused Electronics Factory

The role of the Business Systems Team was to identify the current business activities and look for ways to simplify and streamline these activities by implementing Just-In-Time and Continuous Flow Manufacturing concepts. This team consisted of eleven people from KCD and one consultant.

The People systems Team identified the roles, responsibilities, communication,' and change atmosphere associated with each business function. This team consisted of three people from $\mathrm{KCD}$ and one consultant.

The Information systems Team was commissioned to plan, specify, and implement the necessary strategic Information systems solutions. The consultants worked with this team during the pre-implementation phases of the Focused Electronics Factory. This team consisted of between twenty-five and thirty people from $K C D$ and from four to nine consultants. A consultant was assigned to each sub-project to help facilitate the project activities and a person from $K C D$ was assigned to manage and coordinate the overall team activities and interface with the other teams. 
Enterprise Modeling For The Focused Electronics Factory

SLIDE 6A: Development Methods - The CIMPLAN Approach

The CIMPLAN Approach from Coopers \& Lybrand was used by the Information Systems Team and consisted of four overlapping phases: Orientation, Conceptual Planning, Project specifications, and Implementation.

High-Level "AS-IS" and "TO-BE" process and data models were created during the orientation phase and later used to identify the FEF sub-projects. 
Enterprise Modeling For The Focused Electronics Factory

SLIDE 7: Development Methods - Information Systems Team Projects

Thirteen sub-projects were identified and two enabling systems projects were identified. Five of these sub-projects were related to engineering information and the other eight were related to plant management, control, and production information.

Due to the number of projects identified and FEF resource availability, the effort was divided into two cycles: Cycle 1 included the engineering information systems projects and the enabling systems projects, and cycle 2 included the plant management, control, and production information systems projects. 
Enterprise Modeling For The Focused Electronics Factory

SLIDE 6B: Development Methods - The CIMPLAN Approach

Each of the sub-projects went through the CIMPLAN Conceptual Planning phase (Phase II) to refine and enhance the "TO-BE" process and data models.

At the completion of the Conceptual Planning phase, each sub-project was reviewed to determine if and when it should begin its Project Specifications phase.

Before each sub-project began this next phase, the sub-project material was reviewed and if the project had an emphasis on software requirements then the project switched the SUMMIT-D methodology by coopers \& Lybrand. Otherwise, if the sub-project emphasized hardware requirements then the project continued to use the CIMPLAN Approach to develop its' Project specifications. 
Enterprise Modeling For The Focused Electronics Factory

SIIDE 8: Development Methods - The SUMMIT-D Methodology

The SUMMIT-D Methodology, by coopers \& Iybrand, was a very robust systems Development Life Cycle Methodology that supported projects of varying sizes and purchased or in-house developed solutions.

It provided examples of each deliverable to be produced and identified the methods and techniques used to produce each deliverable.

With a general background of the FEF project, let us review how the FEF sub-project and enterprise model encyclopedias were created and managed. 
Enterprise Modeling For The Focused Electronics Factory

SLIDE 9: Encyclopedia Management - Creation of FEF Project Cycle 1 Encyclopedia

This part of the presentation reviews the evolution of the FEF Enterprise Model Encyclopedia and how it was managed.

During Cycle 1, the five Engineering Information systems projects developed their process and data models using three copies of the Information Engineering Workbench planning and analysis workstations by knowledgeware, Inc. Some of these sub-project teams shared the same analyst workstation and encyclopedia. This caused some confusion and conflicts between analysts because the top level models were always changing as each project analyst entered their information in the same encyclopedia. Also, on the tight schedule for the FEF project, it was difficult to get your information entered into the IEW workstation in a timely manner because of the shared analyst workstations.

There were two people assigned to manage the Master FEF Project Cycle I Encyclopedia on a half-time basis; one KCD analyst and one consulting analyst. Their other duties on the FEF Project did not allow them much time to develop anything but a set of informal undocumented encyclopedia management techniques, guidelines, and data entry standards. 
Enterprise Modeling For The Focused Electronics Factory

The end result of the FEF Project Cycle 1 activities produced the FEF Project cycle 1 Encyclopedia. 


\section{Enterprise Modeling For The Focused Electronics Factory}

SLIDE 10: Encyclopedia Management - creation of FEF Project Cycle 2 Encyclopedia

During Cycle 2, which included the Plant Management, control, and Production Information systems projects, a single process and data model facilitator was assigned with full-time responsibility for the FEF Project Cycle 2 Encyclopedia. This improved the model management process by having only one point of contact for modeling methods and techniques.

Each of the eight sub-project teams analysts worked with the model facilitator to develop a common data model.

The sub-project analysts were primarily responsible for developing their system context diagrams and data flow diagrams.

Problems were encountered in both Cycle 1 and cycle 2 using the IEW Workstation because of differences in the way the project analysts modeled their information and the way the IEW workstation allowed information to be entered based on its knowledge coordinator rules. For example, the technique of leveling data stores could not be used because the IEW workstation carried down, to the next level of detail, the data flows at a higher level from and to a data store. To 
Enterprise Modeling For The Focused Electronics Factory

resolve this problem, we moved the data stores down to the lowest level data flow diagrams where they were used and removed the nonspecific data stores from the higher level data flow diagrams.

The information from the eight sub-projects was consolidated together into the FEF Project Cycle 2 Encyclopedia. 
Enterprise Modeling For The Focused Electronics Factory

SLIDE 11: Encyclopedia Management - Consolidation of FEF Projects

At the end of the Conceptual Planning phase for cycle 2, some of the FEF sub-projects were consolidated together based on common data usage and research of how industry standard software packages grouped their features and functions.

This consolidation effort grouped'nine of the thirteen FEF sub-projects into four sub-project: Manufacturing Resources Planning, Factory Management, Quality Information Management/Traceability, and the CAPP/Work Instructions projects. 
Enterprise Modeling For The Focused Electronics Factory

SLIDE 12: Encyclopedia Management - FEF Projects After Consolidation

After this consolidation effort, their were a total of eight FEF sub-projects of which six were information systems projects and two were the enabling systems projects. 
Enterprise Modeling For The Focused Electronics Factory

\author{
SLIDE 13: Encyclopedia Management - FEF Enterprise Model \\ Encyclopedia Creation
}

When the FEF Project Specifications phase began, it was decided that the cycle 1 and cycle 2 information should be merged into an FEF Enterprise Model Encyclopedia. This process was performed on an IBM PS $/ 2$ Model 80 computer and took several days to complete.

Once this was performed, the enterprise process and data models were reviewed as a whole and modified as necessary to come up with a complete and consistent model of the enterprise. The processes were then mapped back to the FEF sub-projects to identify which sub-project would perform each process in the "TO-BE" model. A data model was then created, for each high-level process, by the sub-project team who owned the process. Then, these high-level process data model views were reviewed and compared against the enterprise data models and were eventually consolidated into the FEF Enterprise Model Encyclopedia. 
Enterprise Modeling For The Focused Electronics Factory

\section{SLIDE 14: Encyclopedia Management - FEF Enterprise Model Management - Conceptual View}

Our current method of enterprise model management consists of two development areas: The Project Model Development Area, and the Enterprise Model Development Area.

In the Project Model Development Area, an encyclopedia is created for each project on a separate analyst workstation using information from the Enterprise Model Encyclopedia. In some cases, multiple encyclopedias are created for a single project if more than one analyst is assigned to a large project. In this case, internal project consolidations occur before any attempt is made to consolidate the project information into the Enterprise Model Encyclopedia.

At the completion of major project deliverables (minor deliverables for a large projects), the project information is transferred to the Enterprise Model Development Area for consolidation into the Enterprise Model Encyclopedia. The transfer takes the form of a backup or consolidation file created from the project encyclopedia which is then restored or loaded into the Enterprise Model Workstation.

After the project information is restored or loaded into the 
Enterprise Modeling For The Focused Electronics Factory

Enterprise Model Workstation, the project information is analyzed and compared against the Enterprise Model information using a Resolution Encyclopedia to perform an initial comparison of the model object lists, and manual analysis techniques are used to identify and resolve model inconsistency issues.

The Project/Enterprise Model Lifecycle diagram that follows shows pictorially how the encyclopedias are managed. 
Enterprise Modeling For The Focused Electronics Factory

SLIDE 15: Encyclopedia Management - FEF Project/Enterprise Model Lifecycle

A new project model encyclopedia is initiated by either creating it from information in the Enterprise Model Encyclopedia, or from scratch depending on what information already exists in the Enterprise Model Encyclopedia.

The project model is then developed by the project team analysts, in the Project Model Development Area, and after completion of major or minor project deliverables is checked into the Enterprise Model Development Area.

After the project model encyclopedia has been restored or loaded into the Enterprise Model Workstation, the project model is compared and analyzed to the Enterprise Model and inconsistency issues are identified and resolved as far as which model should be updated if necessary.

The project model issues are passed back to the project team analysts to update their models and the enterprise model manager makes a backup copy of the enterprise model and updates the Enterprise Model Encyclopedia with any enterprise model issues. 
Enterprise Modeling For The Focused Electronics Factory

When the project model has been updated, it is checked back into the Enterprise Model Development Area and restored or loaded into the Enterprise Model Workstation to go through the model resolution process again and verify that all issues have been incorporated in both the project and enterprise models.

When no model resolution issues are discovered during the Compare/Analyze Models activity, 'then the project model encyclopedia is consolidated into the Enterprise Model Encyclopedia. This consolidation activity synchronizes the two models and updates the Enterprise Model to incorporate any added, changed, or deleted information.

once the consolidate models activity is complete, a project that requires more development can check-out the existing project model information from the Enterprise Model Encyclopedia in the form of a consolidation file.

The project model encyclopedia is then loaded into the project model workstation in the Project Model Development Area to allow the project team analysts to continue the project model development activities. This cycle continues as long as projects require more development. 
Enterprise Modeling For The Focused Electronics Factory

SLIDE 16A: Encyclopedia Management - FEF Compare/Analyze Models

A major effort of the Project/Enterprise Model Lifecycle is the Compare/Analyze Models activity. This activity consists of Generating and Printing the Associated Project and Enterprise Model Encyclopedia Reports and Diagrams, and Performing the Model Comparison and Analysis activities.

The types of reports printed include the standard IEW workstation reports: objects lists, object summaries, and hierarchy reports. The diagrams printed included such things as the decomposition diagrams, data flow diagrams, entity-relationship diagrams, and a special type of subject area entity-relationship diagrams called entity type star diagrams.

These entity type star diagrams (see example slide) play a major role in the data model comparison and analysis activities that precede the model consolidation activity. 
Enterprise Modeling For The Focused Electronics Factory

SLIDE 16B: Encyclopedia Management - FEF Compare/Analyze Models

After all the reports and diagrams are printed, we begin the Compare/Analyze Models Activity. This consists of identifying and resolving Project Guidelines and standards violation issues, and identifying and resolving process and data model inconsistency issues. As mentioned earlier, each issue is resolved to determine whether the project model or enterprise model or neither model should be updated.

I would now like to share with you some of the Model Updating Techniques that we used to incorporate the resolution issues as quickly as possible. 
Enterprise Modeling For The Focused Electronics Factory

SLIDE 17: Encyclopedia Management - FEF Encyclopedia Updating Techniques

To update the process and data models in IEW, we used multiple object lists displayed in the Tiled window format as an index into the encyclopedia. This allows you to quickly access any object of interest in the encyclopedia and to perform such things as: Building new entity type star diagrams using the relationship type object list and the display combine views option, keep a paper trail of changes made to objects or groups of objects before and after each change or group of changes, and update a data flow diagram and its associated data models using the process object list.

Now I would Iike to share with you some of the Enterprise Model statistics. 
Enterprise Modeling For The Focused Electronics Factory

SLIDE 18: Project Results - FEF Enterprise Model statistics

After the first pass consolidation of the FEF sub-projects into the FEF Enterprise Model, here are the Enterprise Model statistics.

For the six information systems projects, we had 405 processes, 520 data flows, 54 data' stores, 204 entity types, and 35 major subject areas.

Finally, I would like to share with you some of the lessons that we learned along the road to implementation. 
Enterprise Modeling For The Focused Electronics Factory

SLIDE 19: FEF Lessons Learned

Some of the lessons we learned along the way were that you don't end up with a High-Level Functional Business Model when you consolidate all your sub-projects. What you do get is a mixture of business functions and high-level processes in the top levels of your enterprise decomposition diagram.

This type of model resulted due to the CIMPLAN Approach from C\&L which primarily focused on business problems and their resolution by taking a diagnostic approach. You should therefore create a High-Level Functional Business Model of your enterprise independent of any information systems projects that currently exist and before you try to consolidate any existing projects into your enterprise model or create any new projects.

At the start of a multi-project development effort, such as the Focused Electronics Factory, you should: Have a formally documented set of Project Guidelines and Standards customized to the methods, techniques, and tools to be used by the project teams, Identify and provide adequate and consistent training for all project team members, Designate one or more people full-time to manage the Enterprise Model information, and Establish a team to integrate and coordinate the 
Enterprise Modeling For The Focused Electronics Factory

information flowing between the systems being specified, developed or purchased, and implemented. This integration team is a must in the multi-project development environment and they should be involved in the daily activities of the project teams.

Next, don't expect your project teams to get a lot of modeling done if they have to share the same workstation and/or use the same IEW encyclopedia. This just leads to a lot of confusion, frustration, and analysts conflicts.

Finally, don't expect the enterprise model manager to know everything about every project and be able to incorporate all the project and enterprise model resolution issues in the proper manner or context.

Thank you for your time!! 


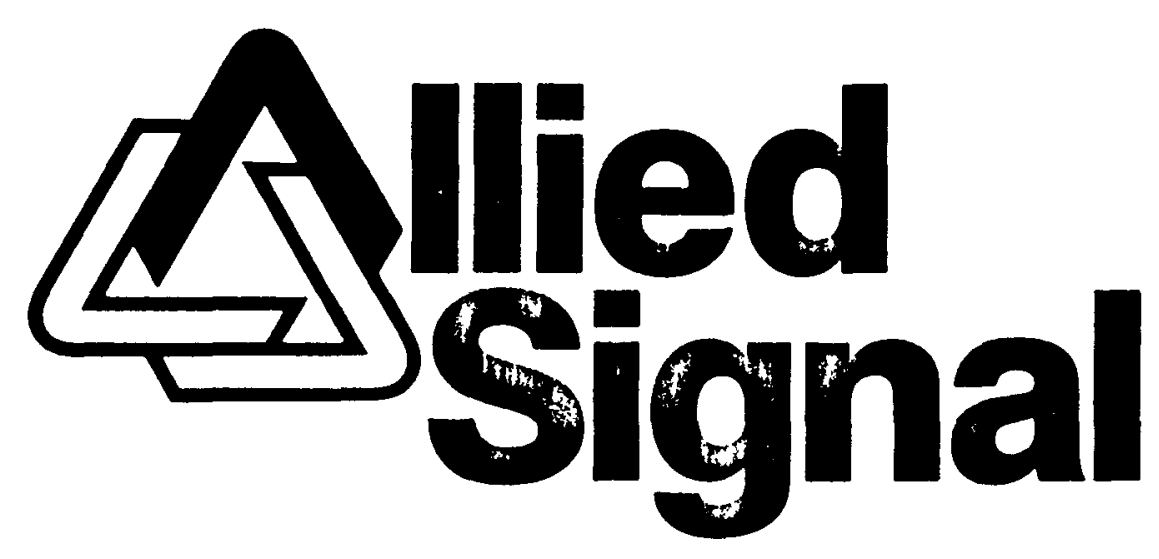

\section{Kansas City Division*}

*Operated for the United States Department of Energy under Contract Number DE-AC04-76-DP00613 


\section{Enterprise Modeling \\ For The Focused Electronics Factory}

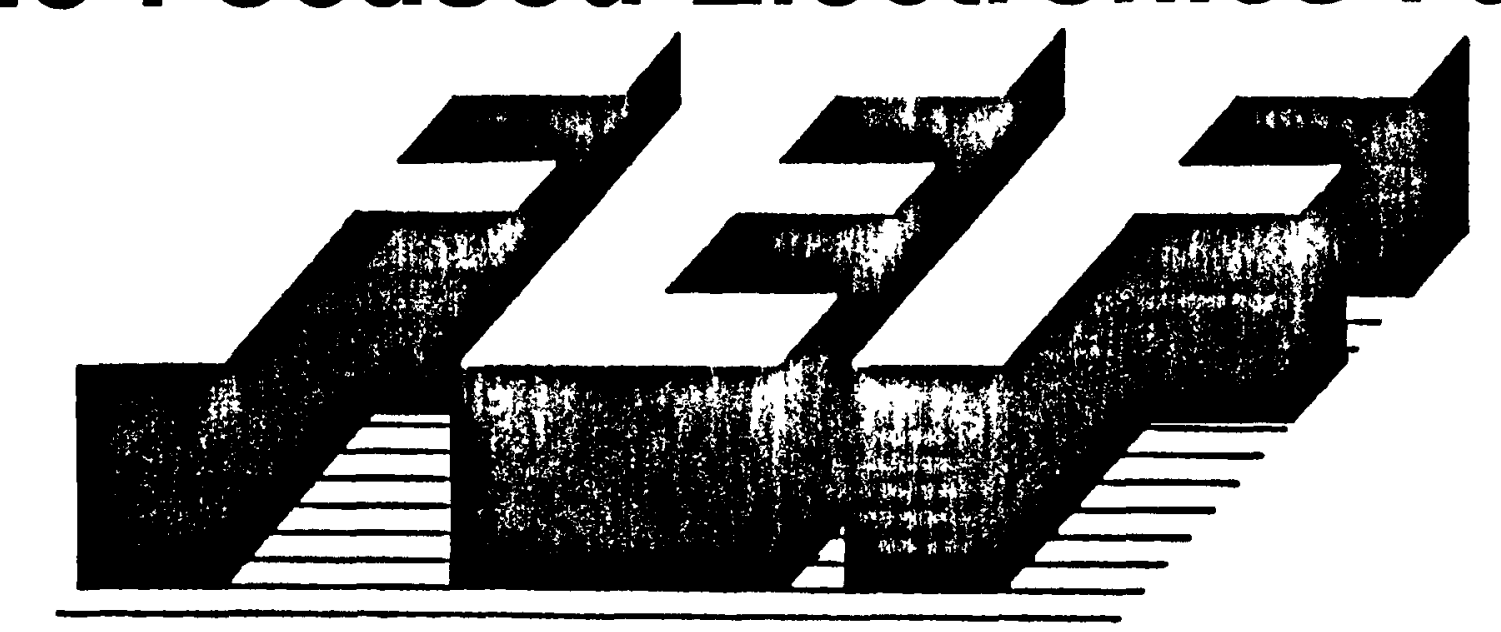

FOCUSEDELECTAEARTCSFACTORY

Presented To:

Kansas City KnowledgeWare Users Group

December 13, 1990

Presentor: Brian N. Oliver 


\section{Enterprise Modeling \\ For The Focused Electronics Factory \\ December 13, 1990}

Agenda:

Background

Development Methods

Encyclopedia Management

Project Results

Lessons Learned 


\section{Purpose:}

The Focused Electronics Factory is a Strategic Business Improvement Initiative to Streamline and Simplify Operations and Systems 


\section{Focused Electronics Factory - Context Diagram}

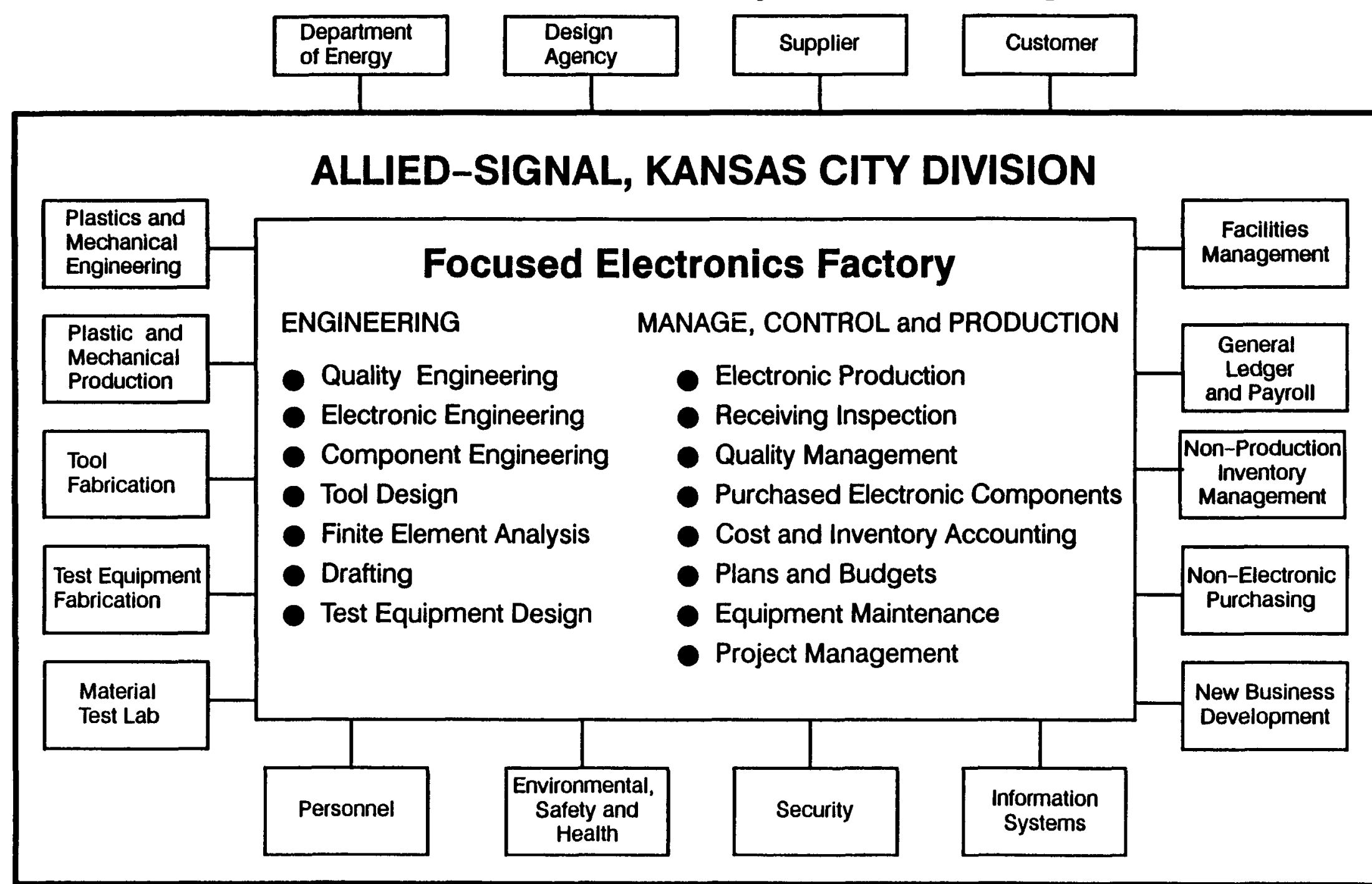

kwug.pres.pg04 12/09/90 


\section{FOCUSED ELECTRONICS FACTORY ORGANIZATIONAL STRUCTURE}

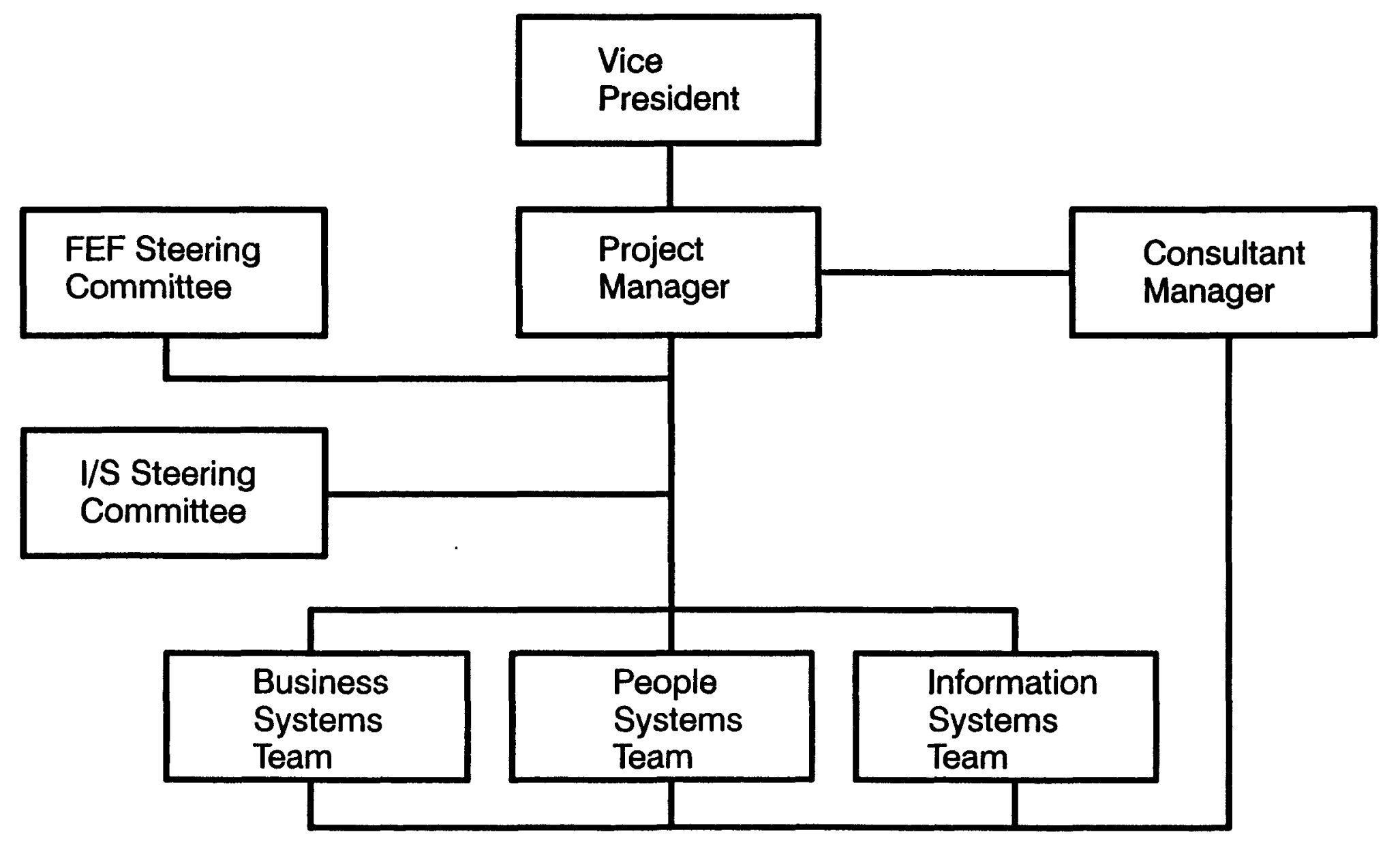




\section{THE CIMPLAN APPROACH}

I. ORIENTATION

- Determine Strategic Directions

- Model Processes \& Information

- Identify Critical Objectives

- Assess Current Position

- Publish Conceptual Vision

II.

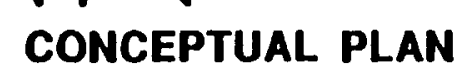

- Define Major Projects

- Investigate Alternative Approaches

- Prepare Integration Plans

- Compare Costs \& Benefits

- Publish Selected Plan
111.

\section{PROJECT SPECIFICATIONS}

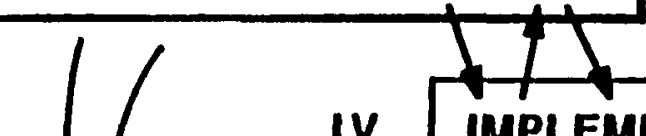
Requirements

- Select Design Alternative

- Assess Integration Constraints

- Refine Budgets \& Schedules

- Publish Project Specifications

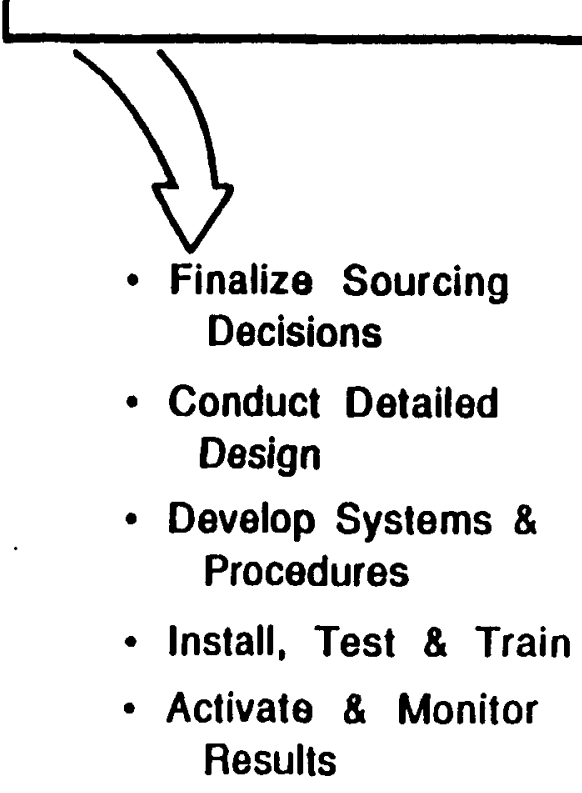




\title{
FOCUSED ELECTRONICS FACTORY INFORMATION SYSTEMS TEAM PROJECTS
}

\author{
ENGINEERING INFORMATION \\ PROJECT 1 DEFINITION CONFIGURATION MANAGEMENT (DCM) \\ PROJECT 2 ELECTRONIC CAE/CAD/CAM INTEGRATION (EDMA) \\ PROJECT 3 CAPP AND WORK INSTRUCTIONS \\ PROJECT 4 PRODUCT GROUP TECHNOLOGY DATABASE \\ PROJECT 5 ENGINEERING PROJECT MANAGEMENT \\ ENABLING SYSTEMS \\ PROJECT 6 COMMUNICATION SYSTEMS (KCIDS) \\ PROJECT 7 INFORMATION SYSTEM RESOURCE MANAGEMENT \\ MANAGE, CONTROL, AND PRODUCTION INFORMATION \\ PROJECT 8 MANUFACTURING PLANNING AND CONTROL \\ PROJECT 9 PURCHASING \\ PROJECT 10 FACTORY MANAGEMENT \\ PROJECT 11 STORES MANAGEMENT \\ PROJECT 12 WORK INSTRUCTIONS \\ PROJECT 13 QUALITY INFORMATION MANAGEMENT \\ PROJECT 14 PERFORMANCE AND COST MANAGEMENT \\ PROJECT 15 TRACEABILITY
}




\section{SUMMIT-D BASIC PHASE AND MODULE STRUCTURE}

Phase

\section{Project Plan \\ \& Initiation}

Pre-Project Summit-D Activities

Module

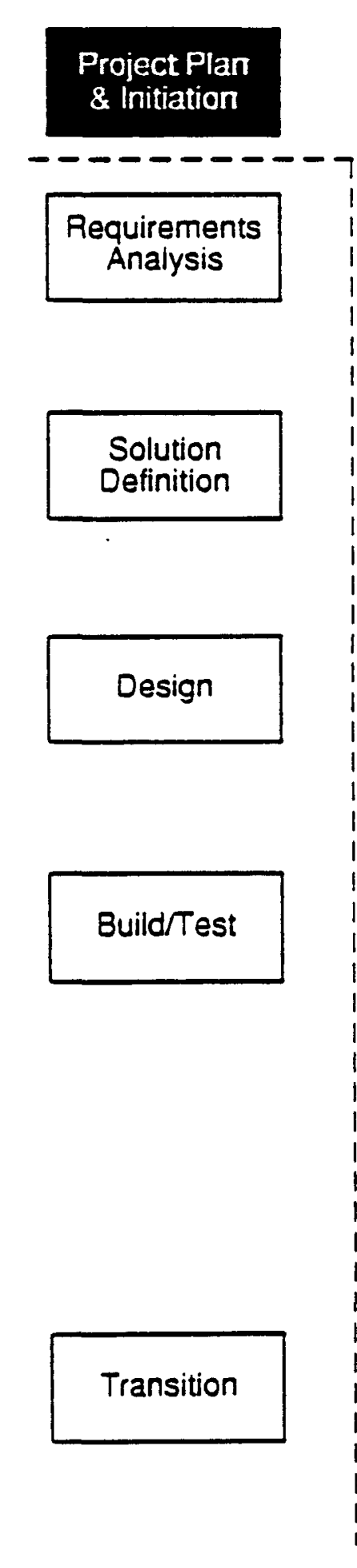

System Requirements
Analysis

- Define "best" solution

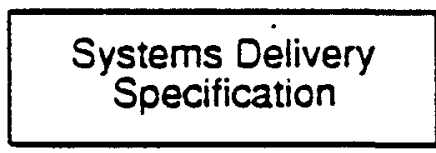

- Define detalled functional needs
Product Evaluation \& Recommendation

- Recommend product

Product Acquisition \& Installation

- Install selected product

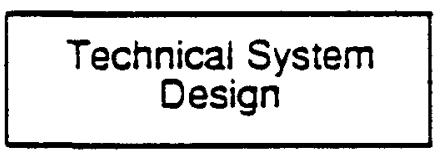

- Design detailed technical solution

\section{Technical Procedure} Development

- Build automated solution

- Train operations

\section{System \& Acceptance} Testing

- Test system

- Accept system

\section{User Procedure} Development

- Build manual solution

- Train users

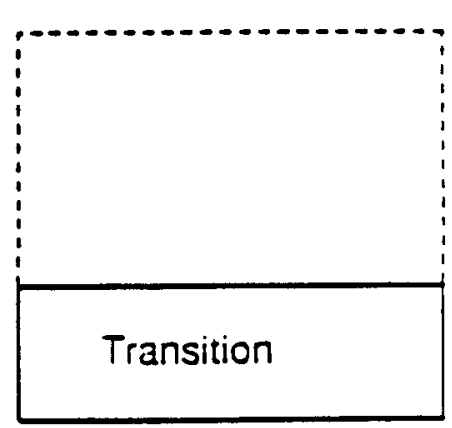

- Cut over and operate new systems

20007 


\section{FOCUSED ELECTRONICS FACTORY CREATION OF CYCLE 1 ENCYCLOPEDIA}

\section{CYCLE 1: Engineering Information}

CIMPLAN PHASE II: Conceptual Planning

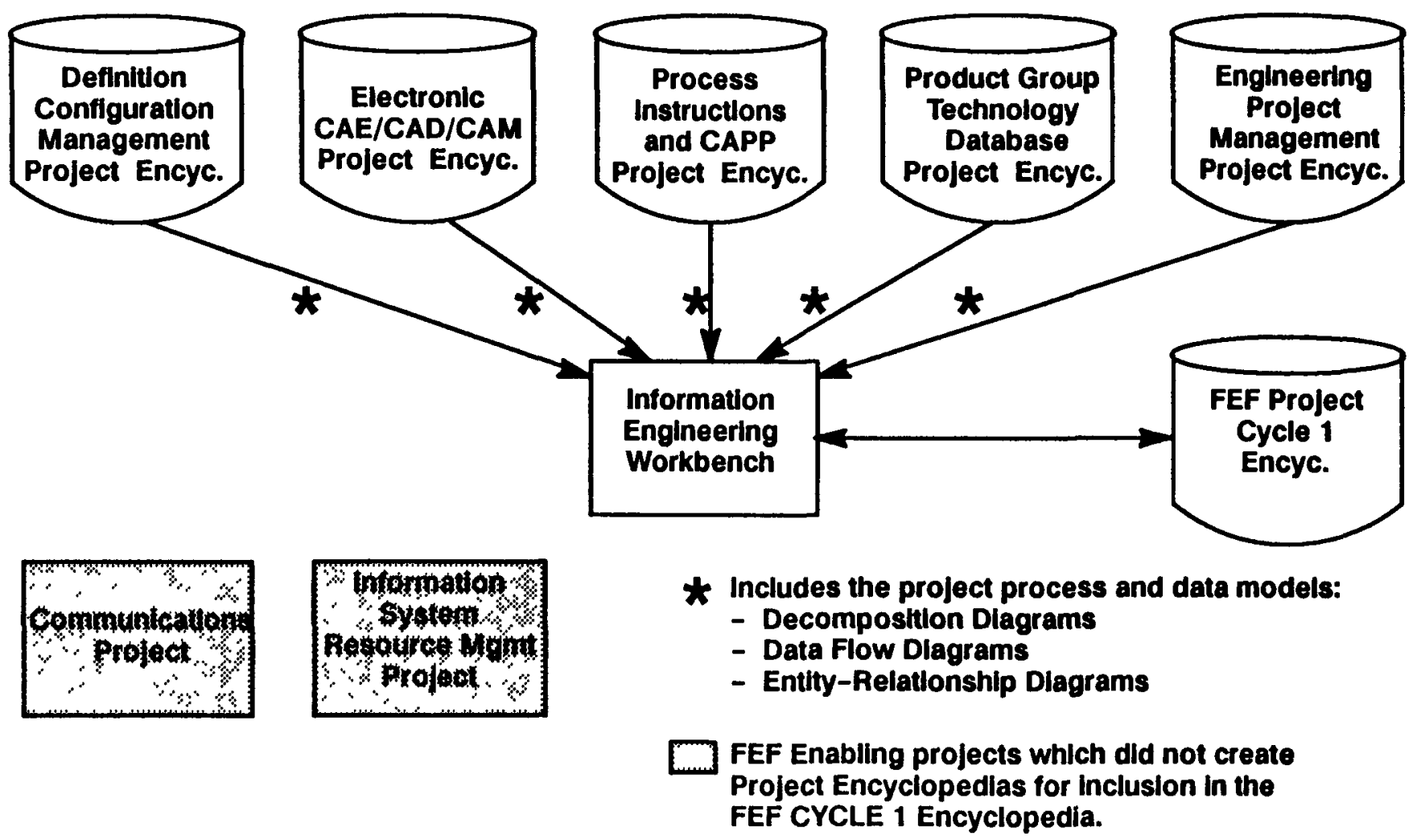




\section{FOCUSED ELECTRONICS FACTORY CREATION OF CYCLE 2 ENCYCLOPEDIA}

CYCLE 2: Manage, Control, and

CIMPLAN PHASE II: Conceptual Planning Production Information

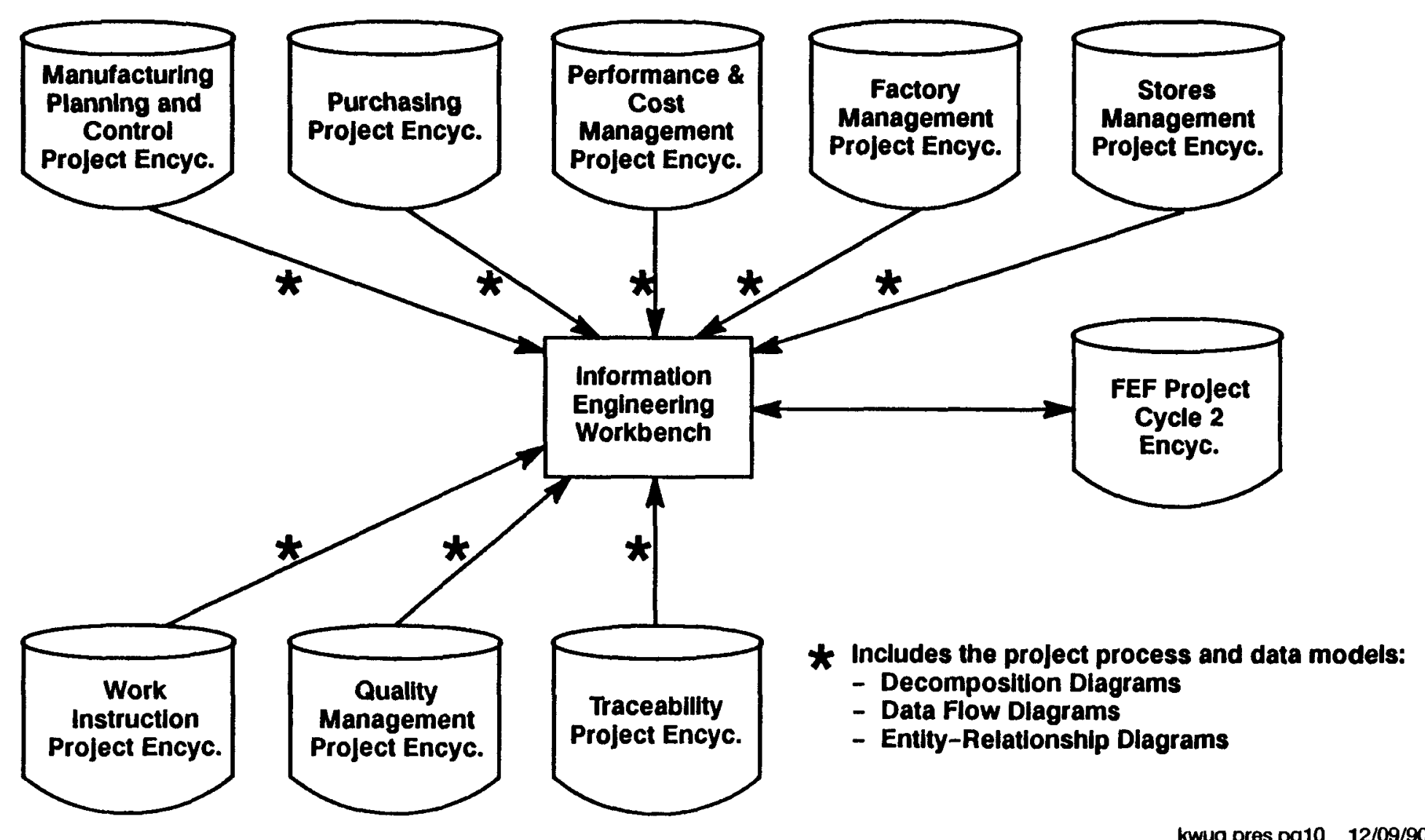

kwug pres pg10 12/09/90 


\section{FOCUSED ELECTRONICS FACTORY CONSOLIDATION OF PROJECTS ${ }^{(1)}$}
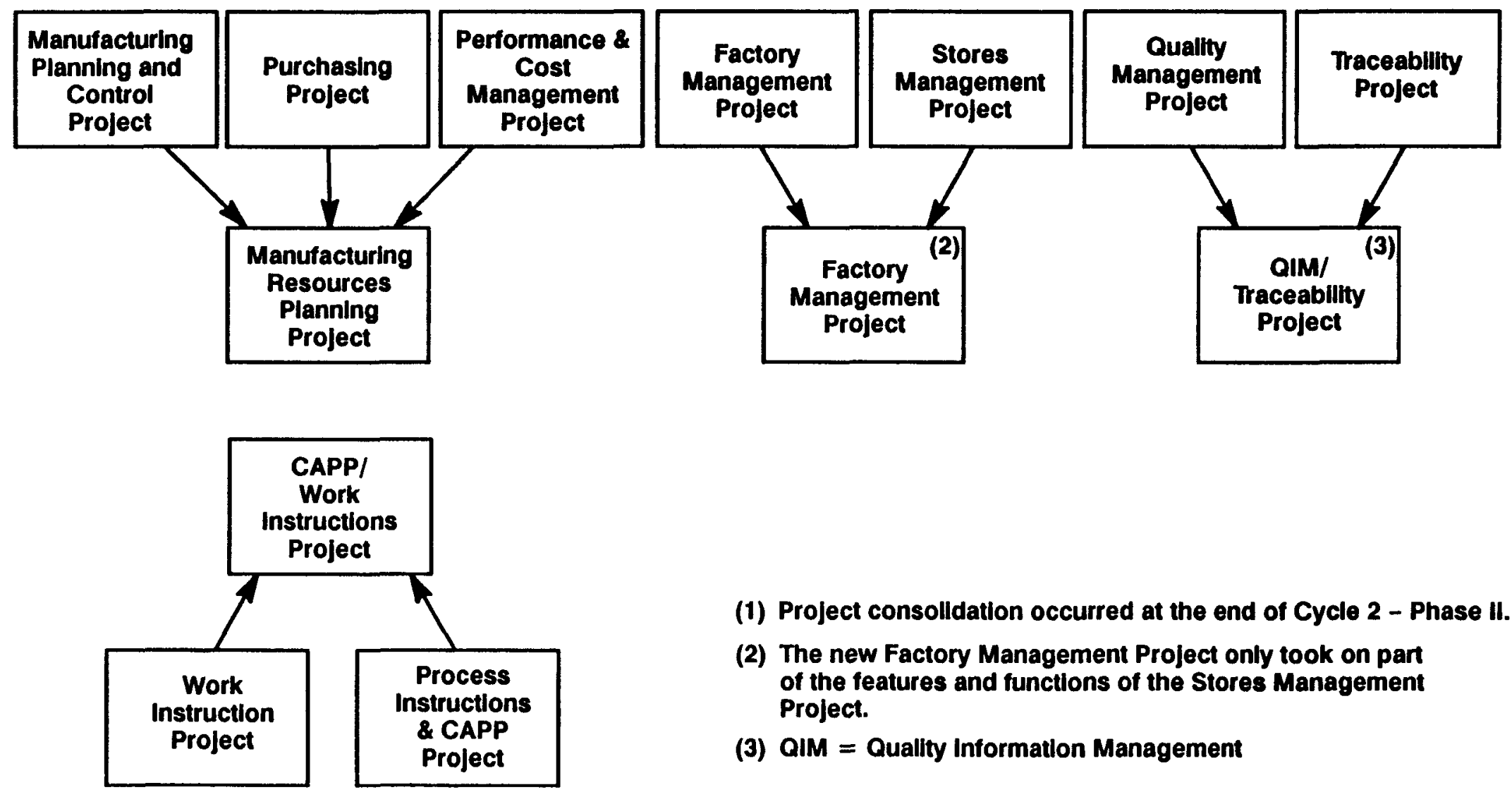

(1) Project consolldation occurred at the end of Cycle 2 - Phase II.

(2) The new Factory Management Project only took on part of the features and functions of the Stores Management Project.

(3) QIM = Quality Information Management 


\section{FOCUSED ELECTRONICS FACTORY PROJECTS AFTER CONSOLIDATION}
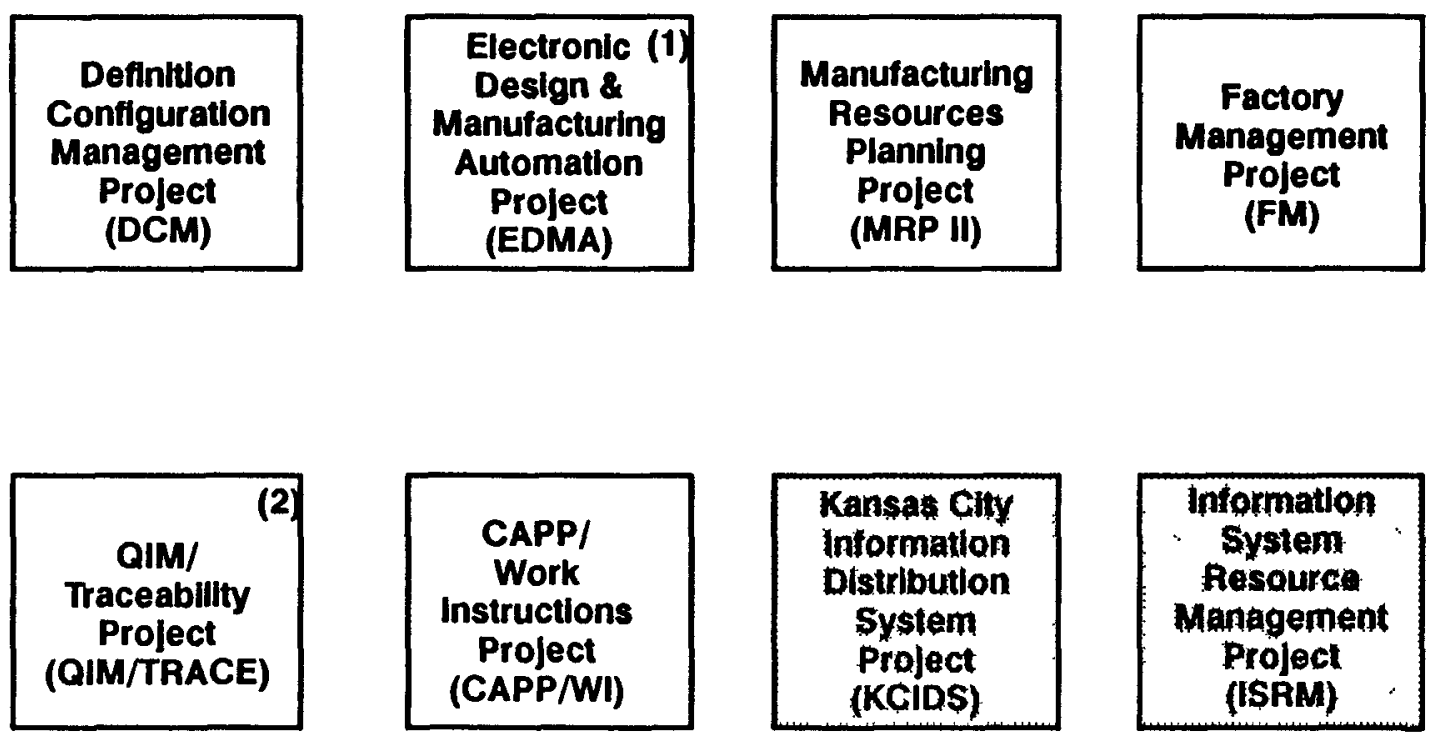

(1) Formally the Electronic CAE/CAD/CAM Project before it became a joint effort between Allled-SIgnal Kansas Clity Dlvision and Sandla Albuquerque.

(2) QIM = Quality Information Management.

$\square$ FEF Enabling projects. 


\section{FOCUSED ELECTRONICS FACTORY ENTERPRISE MODEL ENCYCLOPEDIA CREATION}

\section{CIMPLAN PHASE III: Project Speclfications}

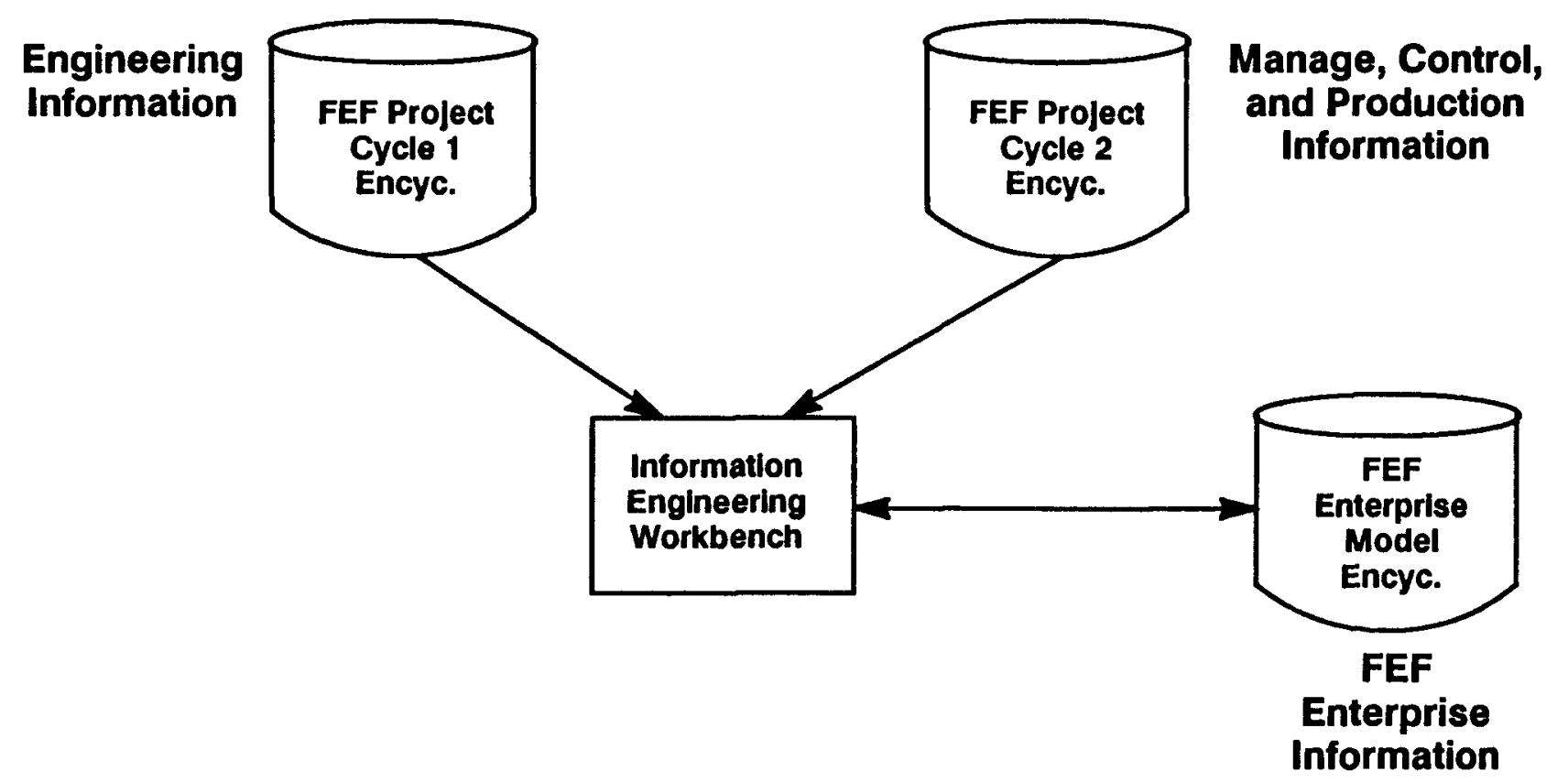




\section{FOCUSED ELECTRONICS FACTORY ENTERPRISE MODEL MANAGEMENT CONCEPTUAL VIEW}

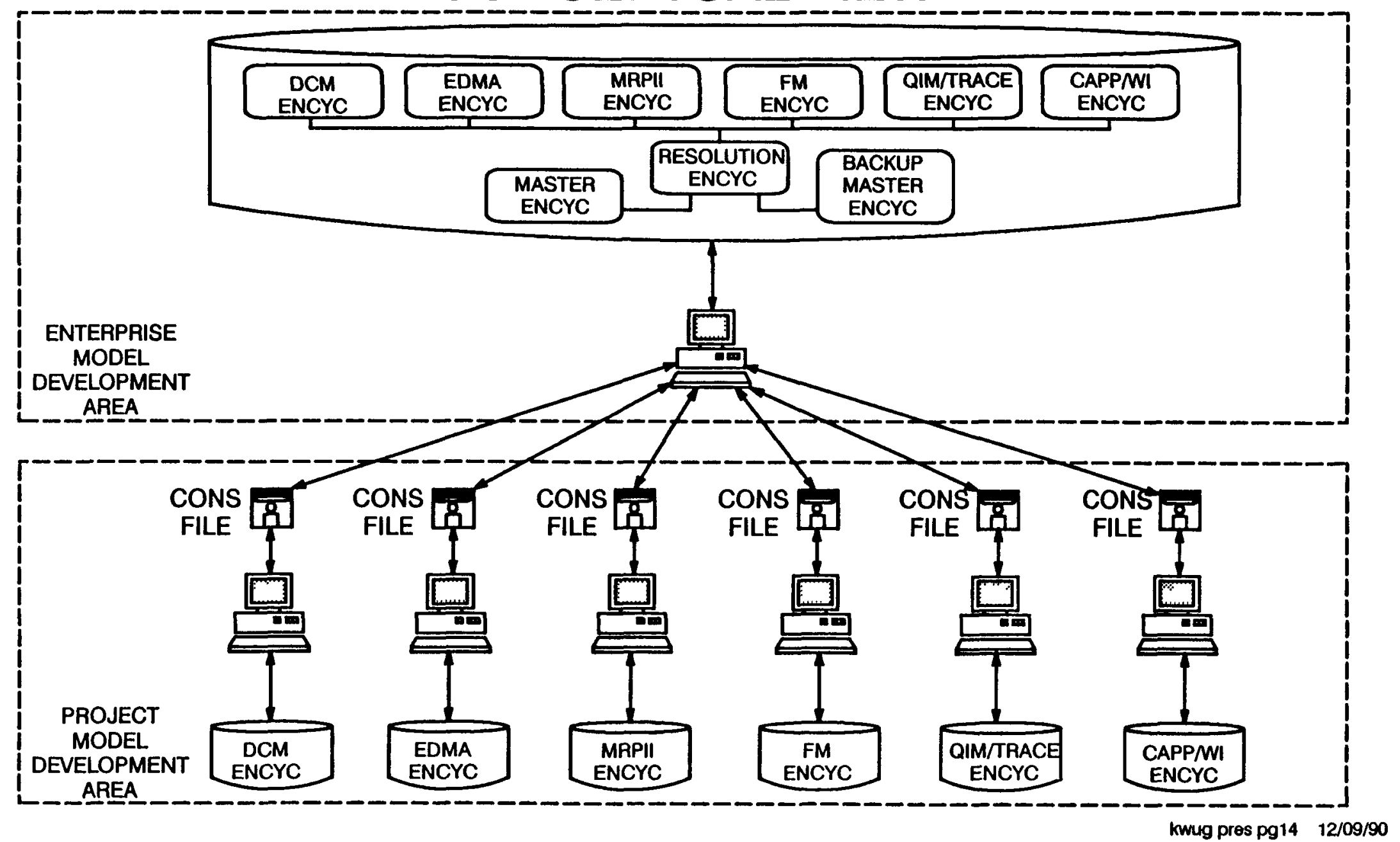




\section{FOCUSED ELECTRONICS FACTORY PROJECT/ENTERPRISE MODEL LIFECYCLE}

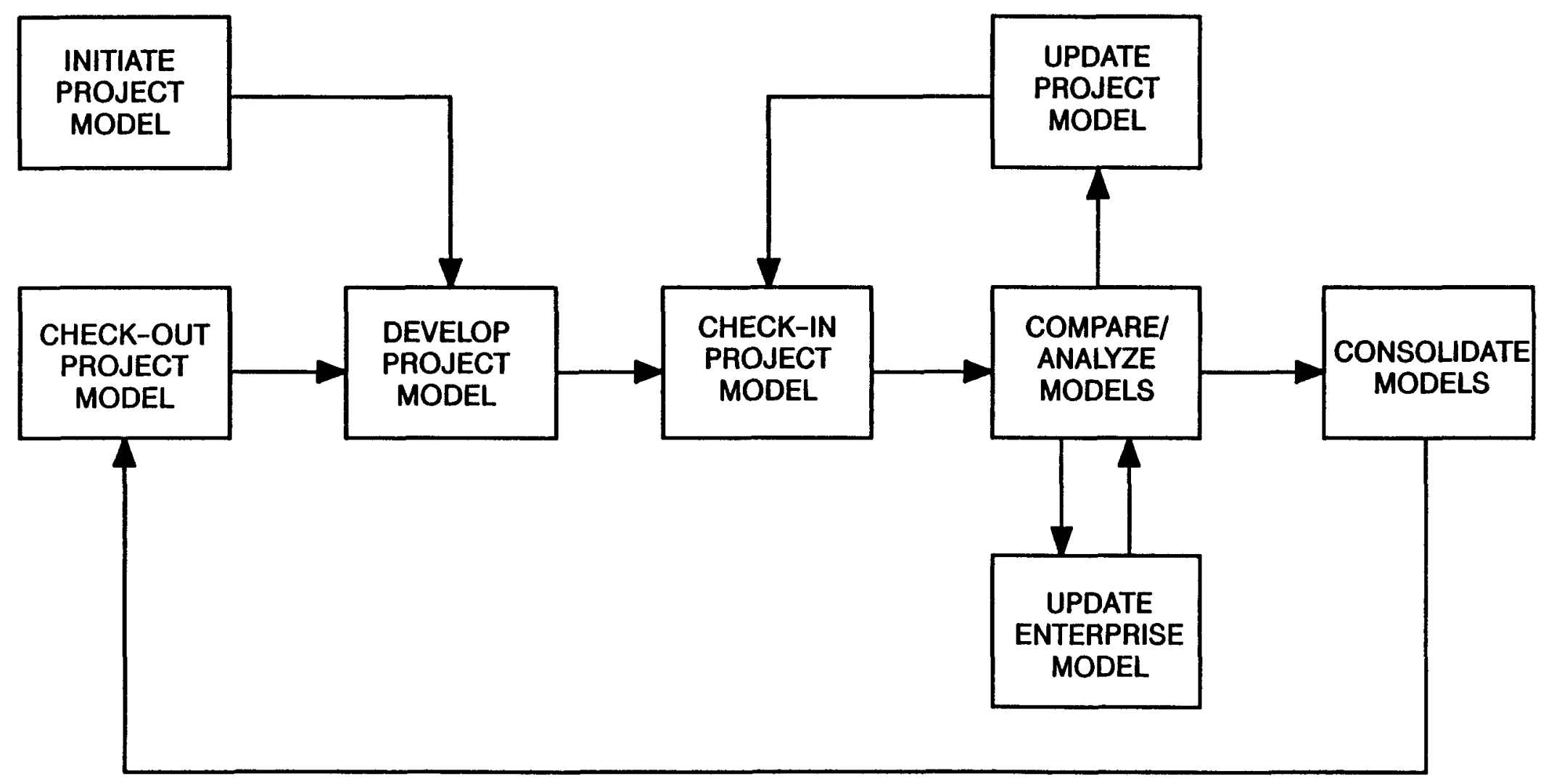

kwug.pres.pg15 12/09/90 


\section{FOCUSED ELECTRONICS FACTORY COMPARE/ANALYZE MODELS}

- Generate and Print Associated Reports and Diagrams

- Standard Textual Reports

- Object List Reports

- Object Summary Reports

- Hierarchy Reports

- Standard Diagrams:

- Decomposition Diagrams

- Data Flow Diagrams

- Entity-Relationship Diagrams

- Entity Type Star Diagrams

- Perform Comparison Analysis

- Identify and Resolve Project Guidelines and Standards Violation Issues

- Naming Standards

- Diagramming Conventions

- Identify and Resolve Process and Data Model Inconsistency Issues

- Duplicate Objects

- Synonymous Objects

- Obvious Match Objects

- New, Updated, or Deleted Objects 


\section{ENTITY TYPE STAR DIAGRAM EXAMPLE: EQUIPMENT}

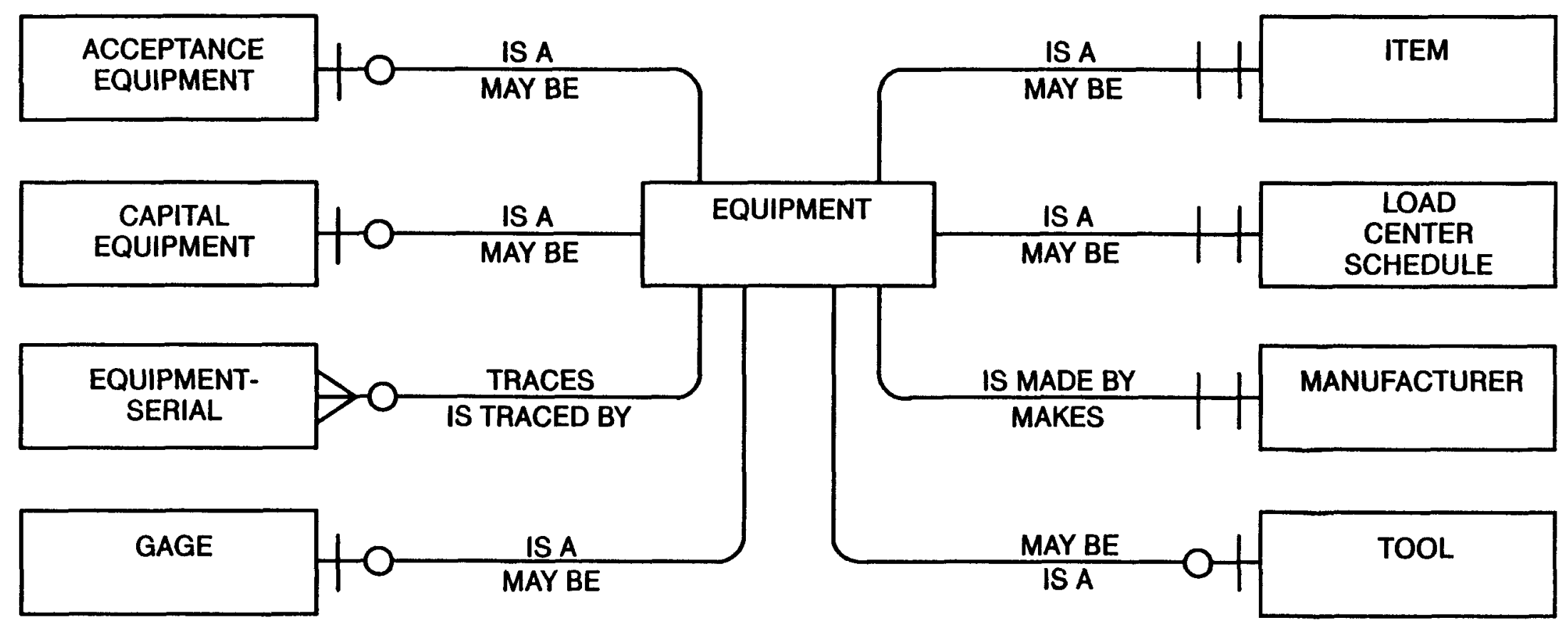

SD-EQUIPMENT 


\section{ENTITY TYPE STAR DIAGRAM}

\section{USES:}

- Provides a way to view and analyze how one Entity Type Contributes to a Project or Enterprise Data Model

- Focuses the Data Collection and Data Validation effort with the User Community

- Focuses the Project or Enterprise Data Model Analysis activities

- Allows you to Easily Identify Violations of the Project and Enterprise Data Model Standards and Conventions 


\section{FOCUSED ELECTRONICS FACTORY ENCYCLOPEDIA UPDATING TECHNIQUES}

- Process and Data Model Updating Techniques

- Display multiple Object Lists in Tiled Windows

- Use Subject Area Object List to:

- Display and Edit Entity Type Star Diagrams

- Display and Edit General Subject Area Entity-Relationship Diagrams

- Use Relationship Type Object List to:

- Build new Entity Type Star Diagrams

- Add additional Entity Types and Relationship Types to an existing Entity Type Star Diagram using Select:By Name... and Display:Combine Views...

- Use Entity Type Object List to:

- Identify new Entity Types that require Entity Type Star Diagrams

- Add, Update, Delete, or Rename Entity Types

- Generate and Print Object Summary Reports before and after changes are made to the model for historical records.

- Use Process Object List to:

- Display and Edit Process Entity-Relationship Diagrams

- Display and Edit Decomposition Diagrams

- Display and Edit Data Flow Diagrams 


\section{FOCUSED ELECTRONICS FACTORY ENTERPRISE MODEL STATISTICS}

PROJECTS

BUSINESS MODEL:

PROCESSES

DATA FLOWS

DATA STORES

DATA MODEL:

ENTITY TYPES

SUBJECT AREAS
$=6$

$$
\begin{array}{ll}
= & 405 \\
= & 520 \\
= & 54
\end{array}
$$

$=204$

$=35$ 


\section{FOCUSED ELECTRONICS FACTORY LESSONS LEARNED}

- Perform Enterprise Modeling before the projects are established

- At the start of a Multi-Project Development Effort

- Establish Formal Project Guidelines and Standards specific to the selected Methods, Techniques, and Tools

- Train all Project Team Members to use the selected Methods, Techniques, and Tools

- Establish an Enterprise Model Manager

- Establish a Project Integration Team

- Create a separate Encyclopedia for each Project

- The Project Team should be responsible for updating their Encyclopedia after the Compare/Analyze Models Activity of the Project/Enterprise Model Life Cycle 


\section{ENTERPRISE MODEL MANAGER}

RESPONSIBILITIES:

- Function and Data Guidelines and Standards

- Set and Enforce Function and Data Management Guidelines and Standards

- Resolves the use of Synonyms and Homonyms

- Enterprise Models

- Builds and Maintains the Business Function and Data Models

- Custodian of the Enterprise Data

- Administration

- Ensures that individual application development supports the global business needs

- Assists the Integration Team in Resolving Interfacing Conflicts that arise between application development projects

- Control Shared Databases 


\section{ENTERPRISE MODEL MANAGER}

\section{BACKGROUND:}

- Management Skills

- Must possess good conflict resolution skills

- Must have good communication skills

- Must have good meeting facilitation skills

- Technical Skills

- Must be proficient in the following skills:

- Process and Data Analysis and Modeling

- Drawing Entity-Relationship Diagrams

- Drawing Data Flow Diagrams

- Building and Maintaining Encyclopedias

- Structured Walkthroughs

- Progress Reporting

- Must be familiar with the following skills:

- Identifying Objectives

- Top Down Development Planning

- Strategic Design

- Change Control

- Business Skills

- Must have a general knowledge about the business

(i.e, Business Functions and Business Organizational Structure)

ent.mdl.mgr.bkgd 12/09/90 